\title{
PERANCANGAN APLIKASI UNTUK MENDETEKSI SABUK PENGAMAN MOBIL MENGGUNAKAN ALGORITMA BACKPROPAGATION NEURAL NETWORK (BPNN)
}

\author{
Abdul Jabbar Lubis ${ }^{1}$, Ade Saprin ${ }^{2}$ \\ ${ }^{1,2}$ Teknik Informatika, Fakultas Teknik dan Komputer Universitas Harapan Medan \\ Jl. HM Jhoni No 70 Medan, Indonesia \\ $\underline{{ }^{1} \text { abduljabbarlbs@gmail.com }}{ }^{2}$ ade.saprin@gmail.com
}

\begin{abstract}
Abstrak - Untuk menegakkan peraturan lalu lintas di jalan raya, petugas kepolisian menghadapi kendala dalam memantau pemakaian sabuk pengaman pada mobil karena mobil di jalan raya senantiasa bergerak dan juga hampir semua mobil menggunakan kaca film untuk menghidari panas matahari masuk ke dalam mobil. Berdasarkan masalah di atas, maka penulis membangun sebuah perangkat lunak yang dapat memantau atau mendeteksi pengemudi memakai sabuk pengaman atau tidak dengan microsoft visual C\# 2010. Untuk memantau pemakaian sabuk pengaman, maka pada penelitian ini digunakan camera digital untuk melakukan akusisi citra yang akan diolah oleh komputer. Selanjutnya citra tersebut dipelajari oleh sistem dengan metode Jaringan Syaraf Tiruan algoritma Back Propagation Neural Network (BPNN) sebagai citra pengemudi yang menggunakan sabuk pengaman. Untuk melakukan deteksi, di input citra pengujian yang berukuran sama dengan citra pelatihan. Hasil pengujian yang diperoleh tingkat akurasi untuk akusisi citra dengan jarak 1 meter dengan tingkat kemiripan memakai sabuk pengaman dengan nilai maksimum 9\% dan tingkat kemiripan tanpa sabuk pengaman kurang dari $4 \%$.
\end{abstract}

\section{Kata Kunci - Citra, Neural Network, Algoritma Backpropagation}

\begin{abstract}
To enforce traffic laws on the highway, police officers facing obstacles in monitoring the use of seatbelts in the car because the cars on the highway constantly moving and also almost all cars use window film to avoid the sun's heat into the car. Based on the above problems, the authors build a software that can monitor or detect the driver wearing a seat belt or not with Microsoft Visual C \# 2010. To monitor the use of seat belts, so in this study used a digital camera to make acquisitions image to be processed by a computer. Furthermore, the image of the system studied by the method of Artificial Neural Network algorithm Back Propagation Neural Network (BPNN) as an image of the drivers who use seat belts. To perform the detection, testing inputted image of the same size with the image of the training. The test results obtained degree of accuracy for image acquisition with a distance of 1 meter with a level of similarity to wear a seat belt with a maximum value of $9 \%$ and the level of similarity without seatbelts less than $4 \%$.
\end{abstract}

\section{Keywords - Image, Neural Network, Backpropagation algorithm}

\section{PENDAHULUAN}

Menurut data dari National Highway Traffic Safety Administration (NHTSA), sabuk pengaman menyelamatkan lebih dari 13.000 nyawa dalam satu tahun. Dari tahun 2004-2008, sabuk pengaman menyelamatkan lebih dari 75.000 nyawa (NHTSA, 2011). Kelalaian penggunaan Sabuk pengaman tidak hanya berakibat fatal bagi pengendara mobil, tetapi akan lebih fatal jika dilakukan oleh pengendara pesawat. Sebagai contoh pada kasus jatuhnya pesawat Hercules C-130 yang di Desa Geplak, Kecamatan Karas, Magetan. Saputra, sebagai salah satu penumpang mengaku tidak memakai sabuk keselamatan yang sudah tersedia di bangku penumpang sejak pesawat tinggal landas meninggalkan Lanud Halim Perdana Kusuma. Selain malas, dia mengaku sudah terbiasa terbang menggunakan Hercules sehingga tidak perlu mengenakan sabuk pengaman. Dan yang lebih parah lagi adalah sebagian besar penumpang lain juga melakukan hal yang sama.

Untuk menegakkan peraturan lalu lintas dijalan raya, petugas kepolisian menghadapi kendala dalam memantau pemakaian sabuk pengaman pada mobil. Ini dikarenakan mobil dijalan raya senantiasa bergerak dan juga hampir semua mobil menggunakan kaca film untuk menghidari panas matahari masuk kedalam mobil.

Berdasarkan masalah diatas, maka penulis membangun sebuah perangkat lunak yang dapat memantau atau mendeteksi pengemudi memakai sabuk pengaman atau tidak. Untuk memantau pemakaian sabuk pengaman, maka pada penelitian ini digunakan camera digital untuk melakukan akusisi citra yang akan diolah oleh komputer. Citra yang diterima oleh komputer adalah citra biner bernilai 0 dan nilai 1 . Selanjutnya data tersebut dipelajari oleh sistem dengan metode Jaringan Syaraf Tiruan algoritma Backpropagation Neural Network (BPNN) untuk memastikan apakah pengemudi menggunakan sabuk pengaman.

Oleh sebab itu penulis memberi judul penelitian ini adalah Perancangan Aplikasi Untuk Mendeteksi Sabuk Pengaman Mobil Menggunakan Algoritma Back Propagation Neural Network (BPNN).

\section{A. Rumusan Masalah}

Rumusan masalah dalam penelitian ini adalah membangun perangkat lunak yang mampu mendeteksi pengendara mobil apakah menggunakan sabuk pengaman atau tidak dengan input citra pengendara 
yang diakusisi pada jarak 1 meter dengan citra sabuk pengaman pada mobil tanpa kaca film.

\section{B. Tujuan Penelitian}

Tujuan dari penelitian ini adalah untuk meningkatkan pengawasan penggunaan sabuk pengaman pada kendaraan roda empat. Kemudian Diperolehnya sebuah perangkat lunak yang dapat melakukan deteksi sabuk pengaman sehingga dapat meningkatkan tertib lalulintas jalan raya bagi pengendara mobil untuk mengurangi korban cedera atau kematian pada kecelakaan mobil.

\section{TINJAUAN KEPUSTAKAAN}

\section{A. Jaringan Syaraf Tiruan}

Jaringan Syaraf Tiruan (JST) adalah suatu metode pembelajaran yang diinspirasi dari jaringan sistem pembelajaran biologis yang terjadi dari jaringan sel syaraf (neuron) yang terhubung satu dengan yang lainnya.[1]

\section{B. Backpropagation Neural Network (BPNN)}

Algoritma pelatihan Backpropagation Neural Network (BPNN) pertama kali dirumuskan oleh Werbos dan dipopulerkan oleh Rumelhart \& Mc.Clelland. Backpropagation neural network merupakan tipe jaringan saraf tiruan yang menggunakan metode pembelajaran terbimbing (supervised learning).[2]

Algoritma ini memiliki proses pelatihan yang di dasarkan pada interkoneksi yang sederhana, yaitu apabila keluaran memberikan hasil yang salah, maka penimbang dikoreksi agar galat dapat diperkecil dan tanggapan JST selanjutnya diharapkan dapat mendekati nilai yang benar.[3]

\section{Pra-pemrosesan (Pre-processing)}

Pra-pemrosesan adalah transformasi input data mentah untuk membantu kemampuan komputasional dan pencari ciri serta untuk mengurangi kesalahan. Pada pra-pemrosesan, citra yang ditangkap oleh sensor akan dinormalisasi agar citra menjadi lebih siap untuk diolah pada tahap pemisahan ciri. Kualitas ciri yang dihasilkan pada proses pemisahan ciri sangat tergantung pada hasil pra-pemrosesan.[4]

\section{Pengolahan Citra Digital}

Citra merupakan istilah lain dari gambar, yang merupakan komponen multimedia yang memegang peranan sangat penting sebagai bentuk informasi visual. Pengolahan citra adalah pemrosesan citra menjadi citra yang kualitasnya lebih baik, bertujuan agar mudah di interpretasi oleh manusia atau mesin (komputer). Beberapa contoh operasi pengolahan citra adalah pengubahan kontras citra, penghilangan derau (noise) dengan operasi penapisan(filtering), penghasilan tepi objek, penajaman (sharpening),pemberian warna semu (pseudocoloring).[4]

\section{E. Format Data Bitmap}

Format bitmap ini cocok digunakan untuk menyimpan citra digital yang memiliki banyak variasi dalam bentuknya maupun warnanya, seperti foto, lukisan, dan frame video. Karakteristik lain dari bitmap yang juga penting adalah jumlah warna yang dapat disimpan dalam bitmap tersebuti ini ditentukan oleh banyak nya bit yang digunakan untuk menyimpan setiap titik dari bitmap yang menggunakan satuan bpp (bit per piksel).[4]

\section{ANALISIS DAN PERANCANGAN}

\section{A. Analisis}

Pada penelitian ini dilakukan Deteksi Sabuk Pengaman Pada Pengendara Mobil Menggunakan Algoritma Back Propagation Neural Network (BPNN). Masalah utama yang dihadapi dalam memantau pemakaian sabuk pengaman pada mobil adalah dikarenakan mobil dijalan raya senantiasa bergerak dan juga hampir semua mobil menggunakan kaca film untuk menghindari panas matahari masuk kedalam mobil. Hal ini yang menyebabkan petugas kesulitan menegakkan peraturan keselamatan di jalan raya.

Input data pada penelitian ini adalah berupa file citra yang akan diubah ke dalam citra biner sebelum dilakukan pembelajaran oleh jaringan. Citra yang di-capture adalah citra manusia yang sedang mengendarai mobil. Citra tersebut adalah citra true color 24 bit dengan format BMP. Untuk mengidentifikasi pemakaian sabuk pengaman tersebut, terlebih dahulu citra pengendara harus melewati beberapa proses agar dapat teridentifikasi dengan baik. Selanjutnya citra tersebut dilakukan pra processing agar sesuai dengan analisa jaringan syaraf tiruan antara lain scalling dengan ukuran yang seragam, sharping, grayscale serta binerisasi.

Pada jaringan syaraf tiruan (JST) terdapat dua proses utama yaitu proses pembelajaran dan proses identifikasi atau pengenalan. Proses pembelajaran adalah memberi pengetahuan terhadap jaringan dengan data pembelajaran yang sesuai. Setelah JST melewati tahap ini maka JST telah siap digunakan untuk mengenali karakter piksel-piksel citra sesuai dengan pengetahuan yang dimilikinya dari proses pembelajaran tersebut. Proses berikutnya adalah pengenalan dimana data yang masuk akan dikenali berdasarkan data yang telah melalui proses pembelajaran sebelumnya.

\section{B. Spesifikasi Perangkat Keras}

Perangkat lunak yang dikembangkan membutuhkan spesifikasi hardware minimal seperti dibawah ini

1). Processor Intel Core 2 Duo

2). Memory RAM 2 GB

3). Harddisk $320 \mathrm{~GB}$

4). VGA Card $512 \mathrm{MB}$

5). Monitor LCD 14

6). Keyboard \& Mouse 
Sedangkan perangkat lunak yang digunakan :

1). Sistem operasi Windows 7 Ultimate

2). Microsoft Visual Studio C\# 2010

\section{Praprosesing Citra}

Pra processing citra berfungsi agar citra yang akan diolah sesuai untuk jaringan syaraf tiruan. Pra processing terdiri dari proses antara lain scalling untuk membuat dimensi citra dengan ukuran yang seragam, sharping untuk mempertajam citra, grayscale untuk menkonversi warna citra menjadi keabu-abuan serta binerisasi yaitu membuat nilai piksel citra antara 0 dan 1.

\section{Scalling}

Proses scalling berfungsi untuk membuat dimensi citra dengan ukuran yang seragam yaitu 100 x 100 piksel.

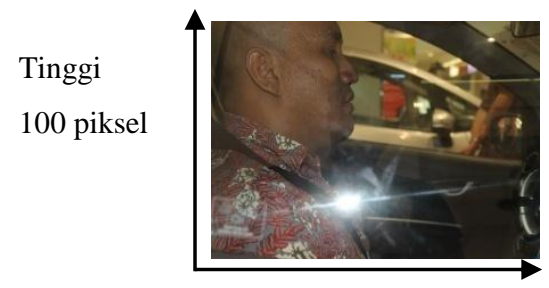

Lebar 100 piksel

Gambar 1. Citra pengendara ukuran 100x100 piksel

\section{E. Sharping}

Penajaman Citra bertujuan memperjelas tepi pada objek di dalam citra. Penajaman Citra dilakukan dengan melewatkan citra pada penapis lolos-tinggi (high-pass filter). Karena penajaman citra lebih berpengaruh pada tepi (edge) objek, maka penajaman citra disebut juga penajaman tepi (edge sharpening) atau peningkatan kualitas tepi (edge enhancement). Akibatnya, pinggiran objek terlihat lebih tajam dibandingkan sekitarnya.

\section{F. Flowchart Umum}

FlowChart Umum adalah bagan yang menggambarkan proses-proses yang secara garis besar dilakukan sistem dalam melakukan training dan pengenalan citra.

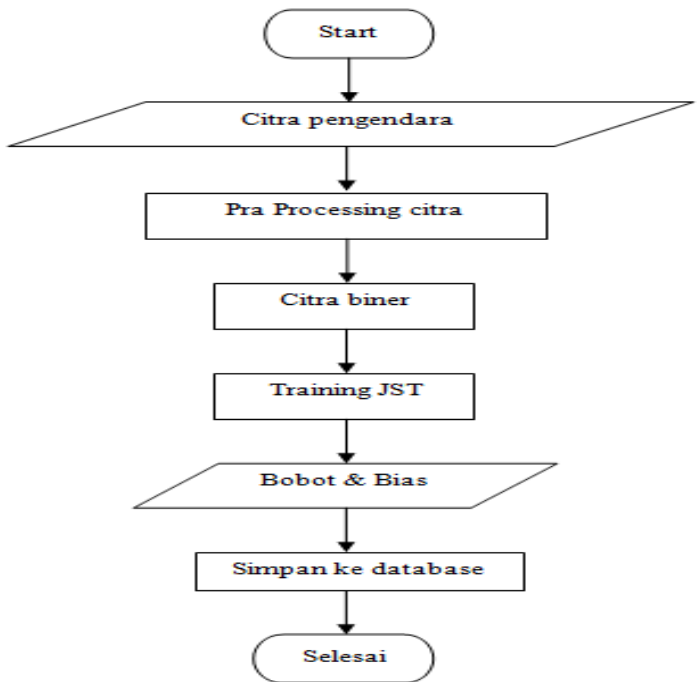

Gambar 2. Flowchart proses Training

Pada gambar di atas, proses awal adalah praprocessing citra adalah proses normalisasi ukuran citra sampai ke binerisasi agar sesuai dengan input jaringan, selanjutnya dilakukan proses training untuk mendapatkan bobot dan biasnya dan disimpan ke database.

Pada Proses pengenalan adalah prosedur yang menjelaskan tentang tahapan pengenalan terhadap citra pengendara kendaraan yang diinput pengguna.

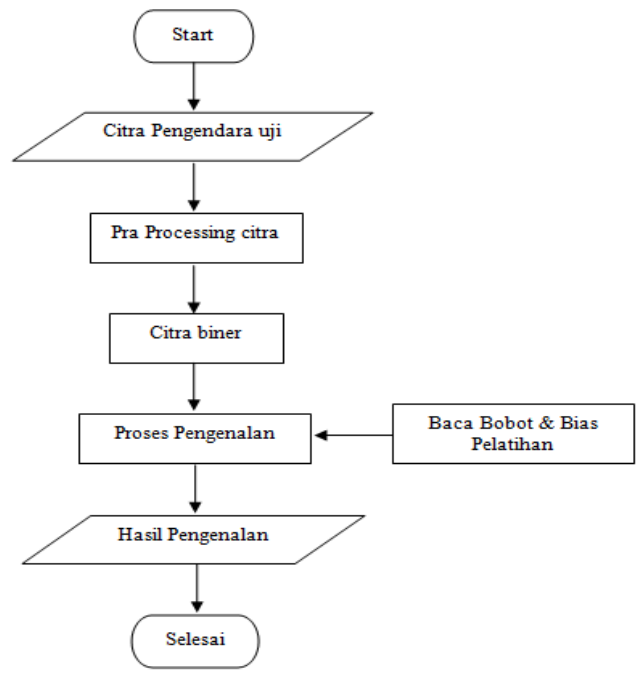

Gambar 3. Flowchart proses Pengenalan

\section{IMPLEMENTASI DAN PENGUJIAN}

Pengujian sistem merupakan gambaran program ketika dirancang didalam bahasa pemrograman, aplikasi untuk Mendeteksi Sabuk Pengaman Mobil dirancang menggunakan bahasa pemrograman $\mathrm{C \#}$.

Dalam penulisan ini, dilakukan pengujian perangkat lunak, mencakup proses setting perangkat lunak dan proses deteksi, serta pengujian kinerja perangkat lunak, yaitu melakukan perbandingan terhadap data training berupa citra pengendara mobil yang memakai sabuk pengaman dan yang tidak memakai sabuk. 
Berikut ini akan dijelaskan mengenai lingkungan pengujian, kasus uji, hasil pengujian dan evaluasi serta kesimpulan hasil pengujian.

\section{A. Form Utama}

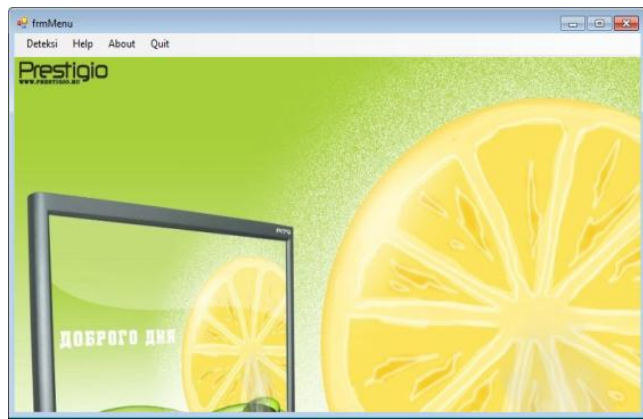

Gambar 4. Form Utama

Gambar 4 merupakan form yang digunakan untuk melakukan deteksi sabuk pengaman. langkah pertama yang harus dilakukan adalah dengan menekan Button "Deteksi".

\section{B. Tampilan Form Setting}

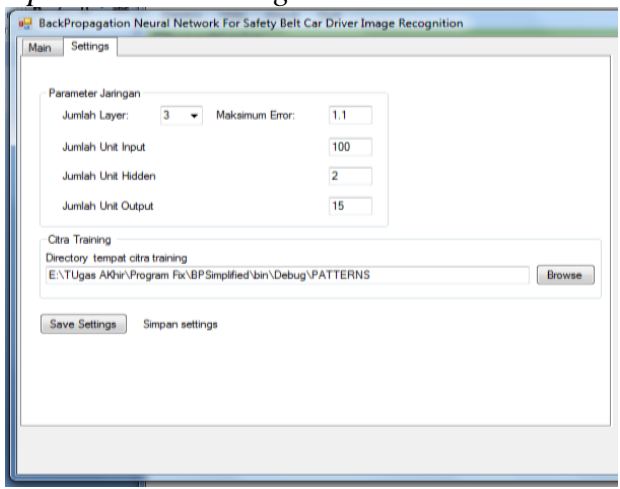

Gambar 5. Form Setting

Tampilan Form Setting berfungsi untuk melakukan pengeditan informasi parameter jaringan serta alamat folder file citra pelatihan.

\section{Tampilan Deteksi}

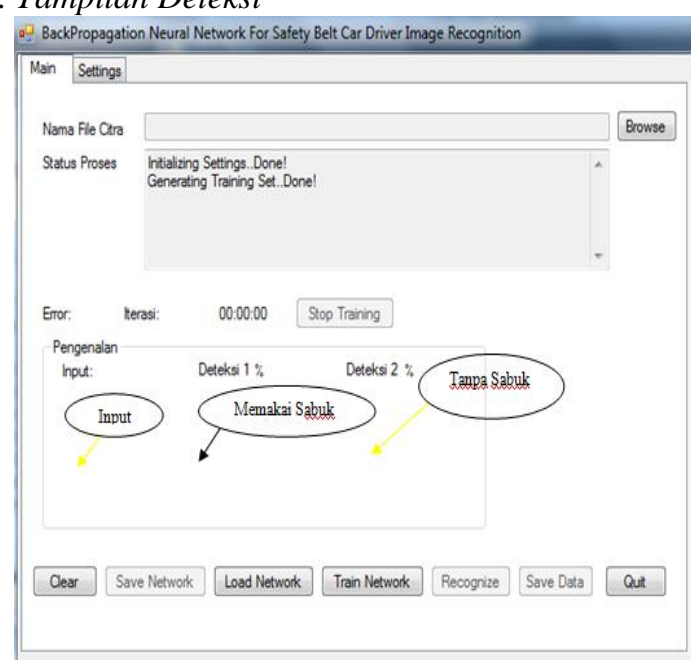

Gambar 6. Form Deteksi
Rancangan Deteksi berfungsi untuk melatih jaringan serta pengenalan citra pengendara yang memakai sabuk pengaman dan tanpa sabuk pengaman.

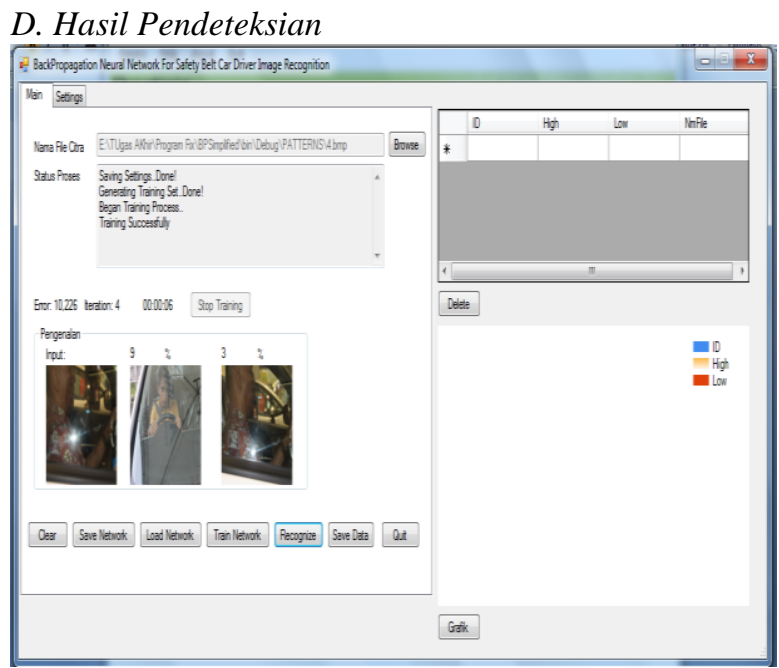

Gambar 7. Hasil Deteksi

Pada Gambar 7 diatas terlihat hasil pengenalan citra sabuk pengaman tanpa kaca film dengan nama file 4.bmp memiliki kemiripan tertinggi menggunakan sabuk pengaman sebesar $9 \%$ dan terendah sebesar $3 \%$ yaitu pengendara tanpa sabuk pengaman dengan nilai error 10.226 dan nilai iterasi 4 .

\section{Kesimpulan}

Adapun kesimpulan dari perangkat lunak dan metode yang dirancang adalah sebagai berikut:

1. Aplikasi dapat melakukan pemasukan data citra pengendara mobil yang memakai sabuk pengaman dan tanpa sabuk pengaman.

2. Aplikasi hanya dapat melakukan sekali training atas citra yang dinput dan untuk melakukan training selanjutnya maka aplikasi harus di setting kembali.

3. Aplikasi ini hanya dapat mendeteksi pengendara roda empat tanpa kaca film.

4. Tingkat akurasi pada aplikasi ini untuk mendeteksi pengendara roda empat tanpa kaca film dengan kemiripan menggunakan sabuk pengaman dengan nilai maksimum $9 \%$ dan tingkat kemiripan tanpa sabuk pengaman kurang dari $4 \%$.

5. Aplikasi ini dapat mengenali sabuk pengaman pada citra dengan akusisi jarak 1 meter.

\section{Daftar Pustaka}

[1] Sutojo \& Mulyanto, E. 2010. Kecerdasan Buatan.Yogyakarta : ANDI.

[2] Septiarini, A. \& Nur Sya'Baniah, N.S, 2012. Sistem Peramalan Jumlah Produksi Air PDAM Samarinda Menggunakan Jaringan Syaraf Tiruan Backpropagation. Jurnal 
EKSPONENSIAL Volume 3, Nomor 1, Mei 2012. Program Studi Statistika FMIPA Universitas Mulawarman.

[3] Muis,S., 2006. Teknik Jaringan Saraf Tiruan, Graha Ilmu, Yogyakarta.

[4] Putra, D. 2010. Pengolahan Citra Digital.Yogyakarta. Penerbit: ANDI. 